\title{
Thermal and Structural Performance of a Single Tube Support Post for the Superconducting Super Collider Dipole Magnet Cryostat
}

W.N. Boroski, T.H. Nicol, M.K. Ruschman and C.J. Schoo

Fermi National Accelerator Laboratory

P.O. Box 500, Batavia, Illinois 60510

July 1993

Presented at the Cryogenic Engineering Conference, Albuquerque, New Mexico, July 12-16, 1993 


\section{Disclaimer}

This report was prepared as an account of work sponsored by an agency of the United States Government. Neither the United States Government nor any agency thereof, nor any of their employees, makes any warranty, express or implied, or assumes any legal liability or responsibility for the accuracy, completeness, or usefulness of any information, apparatus, product, or process disclosed, or represents that its use would not infringe privately owned rights. Reference herein to any specific commercial praduct, process, or service by trade name, trademark, manufacturer, or otherwise, does not necessarily constitute or imply its endorsement, recommendation, or favoring by the United States Government or any agency thereof. The views and opinions of authors expressed herein do not necessarily state or reflect those of the United States Government or any agency thereof. 


\title{
THERMAL AND STRUCTURAL PERFORMANCE OF A SINGLE TUBE SUPPORT POST FOR THE SUPERCONDUCTING SUPER COLLIDER DIPOLE MAGNET CRYOSTAT
}

\author{
W.N. Boroski, T.H. Nicol, M.K. Ruschman, and C.J. Schoo \\ Fermi National Accelerator Laboratory \\ Batavia, Illinois 60510
}

\begin{abstract}
The reentrant support post currently incorporated in the Superconducting Super Collider (SSC) dipole cryostat has been shown to meet the structural and thermal requirements of the cryostat, both in prototype magnet assemblies and through component testing. However, the reentrant post design has two major drawbacks: tight dimensional control on all components, and cost driven by these tolerance constraints and a complex assembly procedure. A single tube support post has been developed as an alternative to the reentrant post design. Several prototype assemblies have been fabricated and subjected to structural testing. Compressive, tensile, and bending forces were applied to each assembly with deflection measured at several locations. A prototype support post has also been thermally evaluated in a heat leak measurement facility. Heat load to $4.2 \mathrm{~K}$ was measured with the intermediate post intercept operating at various temperatures while thermometers positioned along the conductive path of the post mapped thermal gradients. Results from these measurements indicate the single tube support post meets the design criteria for the SSC dipole magnet cryostat support system.
\end{abstract}

\section{INTRODUCTION}

The present suspension system for the SSC 50mm Collider Dipole Magnet (CDM) includes five reentrant post assemblies to support and position the superconducting magnet assembly. The reentrant post meets design requirements for the CDM cryostat, but is expensive to manufacture due to tight dimensional tolerances and a detailed assembly process. Efforts at Fermilab have produced an alternate post design that would replace the current reentrant post with a single tube support post ${ }^{1}$. The initial design analysis, accomplished through finite element modeling, indicates the post will meet the design specifications listed in Tables 1 and 2 . In order to verify the modeling results, several prototype assemblies were fabricated and subjected to structural and thermal testing. 
Overall cold mass weight:

Lateral load requirement:

Vertical load requirement:

$11,360 \mathrm{~kg}$

$1.0 \mathrm{~g}$

Axial load requirement:

$2.0 \mathrm{~g}$

Allowable composite material stress:

$1.5 \mathrm{~g}$

$50 \%$ oult

Table 2. $50 \mathrm{~mm}$ collider dipole heat load budget per support.

\begin{tabular}{c} 
Temperature station \\
\hline $4.5 \mathrm{~K}$ \\
$20 \mathrm{~K}$ \\
$80 \mathrm{~K}$
\end{tabular}

\begin{tabular}{c} 
Budget heat load \\
\hline $0.032 \mathrm{~W}$ \\
$0.480 \mathrm{~W}$ \\
$3.160 \mathrm{~W}$
\end{tabular}

\section{SINGLE TUBE SUPPORT POST DESIGN}

The single tube support post actually consists of two composite tubes connected in series along the thermal path of the assembly. In this respect, the term "single-tube" is somewhat misleading. Here, the "single-tube" descriptor refers to the non-reentrant nature of the design. A fiberglass reinforced composite (FRP) tube is used for the temperature region from $300 \mathrm{~K}$ to $20 \mathrm{~K}$. For the temperature region from $20 \mathrm{~K}$ to $4.5 \mathrm{~K}$, a graphite reinforced composite (GRP) tube is used. The composite tubes are joined together by capturing overlapping sections of each tube between the inner disc and outer ring that comprise the $20 \mathrm{~K}$ heat intercept connection. The overlapped composite tubes are captured and held together through a shrink-fit joint configuration; there are no adhesives or mechanical fasteners present. The single tube post assembly is illustrated in Figure 1.

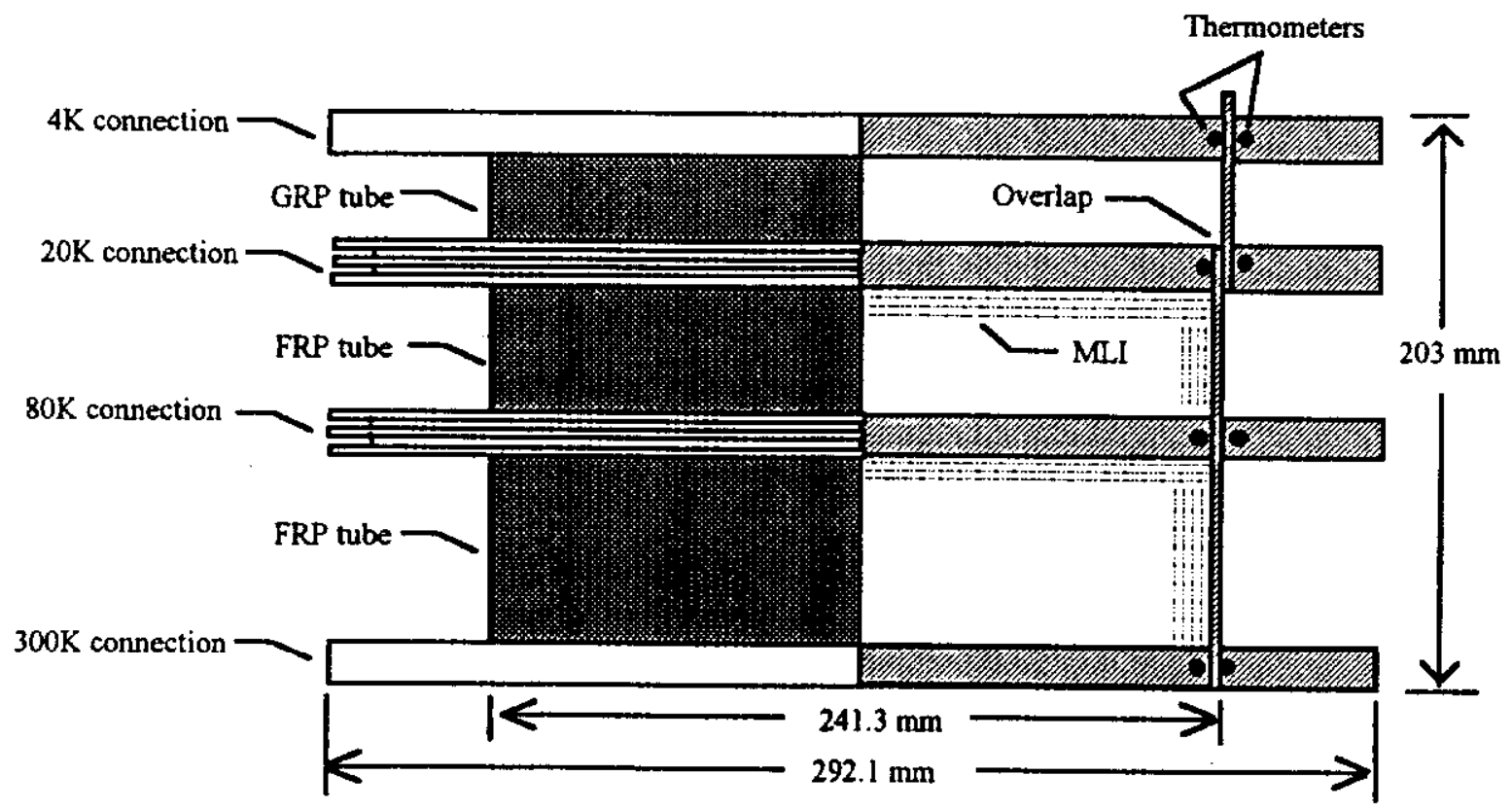

Figure 1. Single tube support post assembly. 
The support post $300 \mathrm{~K}$ and $4 \mathrm{~K}$ connections are comprised of stainless steel rings and discs fastened to the composite tubes using shrink-fit technology. The $80 \mathrm{~K}$ and $20 \mathrm{~K}$ heat intercept stations also employ shrink-fit technology, using aluminum components in place of stainless steel. MLI discs comprised of double-aluminized Mylar reflectors with spunbonded polyester spacers are located below the $20 \mathrm{~K}$ and $80 \mathrm{~K}$ inner discs to impede radiant heat transfer internal to the support assembly.

Prototype post assemblies for the structural and thermal test programs were assembled in a manner representative of a production post with the exception of some additional machining on the metal parts to accommodate instrumentation sensors and leadwires. Assembly of the prototype post was straightforward with no problems encountered.

\section{STRUCTURAL TEST PROGRAM}

Four prototype assemblies were fabricated and subjected to load testing in a structural test fixture. Tensile, compressive, and bending loads were applied to each post at a point equivalent to the superconducting magnet centerline to simulate actual loads applied during shipping, handling, and cryostat operation. The $300 \mathrm{~K}$ end of the post assembly was fixed to the base plate of the test fixture; the $4 \mathrm{~K}$ end of the post was free to move in all directions. Tensile and compressive loads were applied in $454 \mathrm{~kg}$ increments to $4540 \mathrm{~kg}$; lateral loading was applied in $227 \mathrm{~kg}$ increments to $3400 \mathrm{~kg}$. Deflection at the magnet centerline equivalent was measured and recorded at each increment.

\section{STRUCTURAL TEST RESULTS}

Figure 2 illustrates the results from lateral load tests performed on reentrant and single tube support posts. Plotted is the deflection of the superconducting magnet (cold mass) centerline as a result of an applied lateral load to each post type. The results indicate that the single tube design is structurally sound and can meet the structural specifications established for the $50 \mathrm{~mm}$ CDM suspension system.

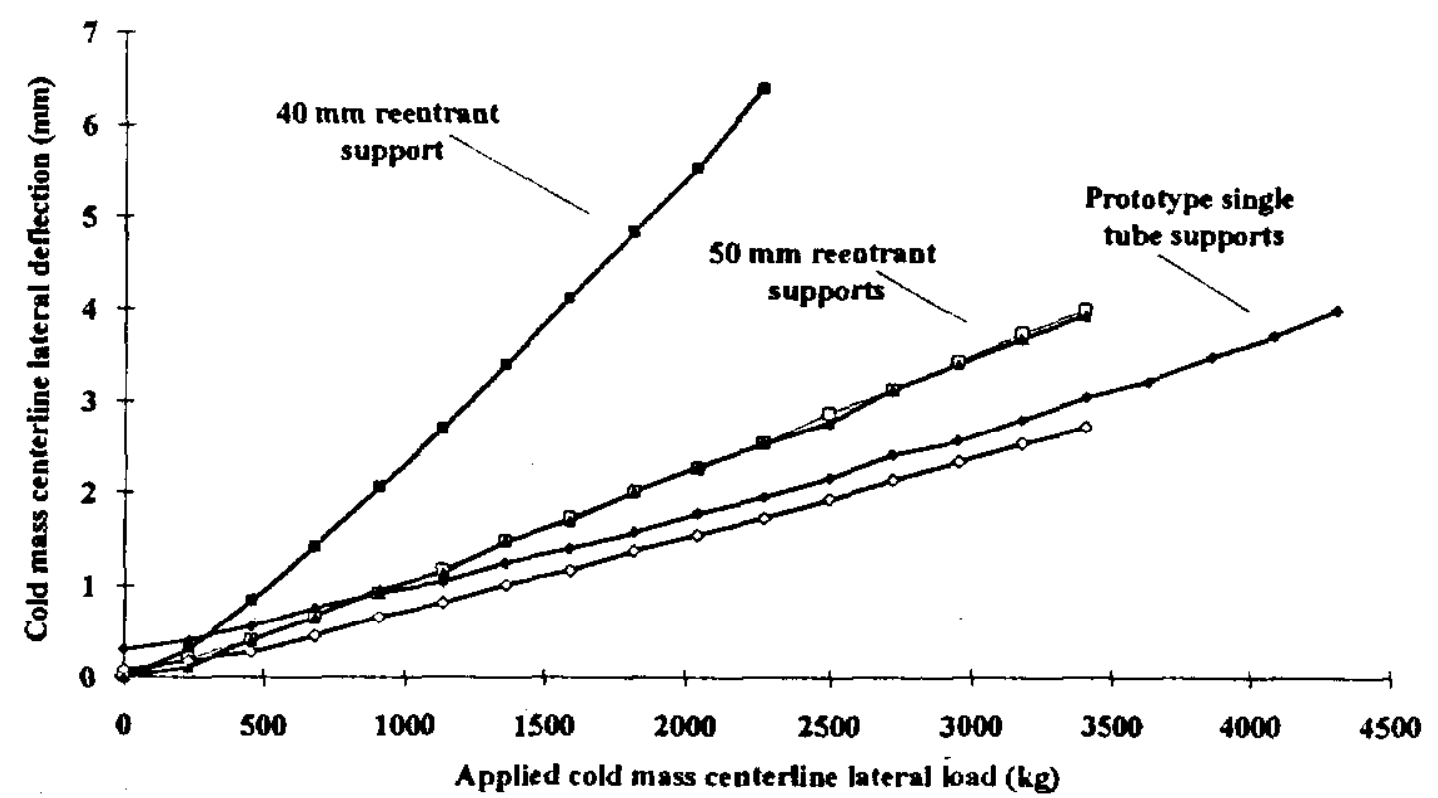




\section{Support Post Instrumentation}

One prototype assembly was assembled and instrumented with thermometers to quantify overall thermal performance and provide thermal gradient mapping. Thermometers were positioned along the conductive path of the support assembly to map the temperature of the various metal components under different operating conditions. This placement is illustrated in Figure 1. 100-ohm platinum RTD's were inserted into holes drilled in the 80K and $300 \mathrm{~K}$ discs and rings respectively. The thermometers were positioned as near to the composite tube as possible to obtain a reasonable measurement of the thermal gradient across each shrink-fit joint. Each RTD was connected in a four-wire configuration using both copper and manganin lead-wire. Twisted pairs of 36 AWG copper wire were soldered directly to the sensor leads and then varnished into a groove machined in each metal part. GE 7031 varnish was used to thermally-anchor the lead-wires into the grooves, which were machined such that the copper lead-wires from each sensor completed one circumferential revolution around the metal part. Once the varnish had cured, twisted pairs of $32 \mathrm{AWG}$ manganin lead-wire were soldered to the copper wires.

Calibrated $100 \Omega$ Allen-Bradley carbon-composition resistors were used as thermometers on the $20 \mathrm{~K}$ and $4 \mathrm{~K}$ metal components. The resistors were installed and wired in a manner similar to that described for the platinum thermometers.

\section{Measurement System Configuration}

Figure 3 illustrates the HLMF with the single tube post in place. Total heat flow through the support assembly to $4 \mathrm{~K}$ was measured by means of a heatmeter that measures heat flow as a temperature gradient across a thermal impedance with an accuracy of $\pm 1 \mathrm{~mW}$ at $4.2 \mathrm{~K}$. The $4 \mathrm{~K}$ disc of the support post is attached to the "warm" end of the heatmeter through a threaded connection; the "cold" end of the heatmeter is attached to the HLMF through a similar threaded connection. Temperature of the heatmeter is established and held constant by pool-boiling helium near $4.2 \mathrm{~K}$ and 1 atmosphere.

To provide cooling of the support post thermal stations, aluminum shields were attached to the support post $20 \mathrm{~K}$ and $80 \mathrm{~K}$ intercept rings through stitch-welded connections. This connection is different from that in the actual cryostat where copper thermal shorting straps are used to thermally connect the intercepts to the shield. There were no copper shorting straps attached to the post for these measurements.

One objective of this measurement was to measure total heat load to $4.2 \mathrm{~K}$ with the primary intercept operating at temperatures between $10 \mathrm{~K}$ and $40 \mathrm{~K}$. To accomplish this, the thermal shield attached to the support post primary intercept was anchored to a variable temperature flange through a bolted connection. Temperature variation of the flange was accomplished by varying the flow rate of helium boil-off gas from the HLTF storage vessels through a tube in good thermal contact with the flange.

The $80 \mathrm{~K}$ heat intercept was cooled by an outer radiation shield that was bolted to the bottom of a liquid nitrogen reservoir. The shield encompassed that portion of the support assembly from the $80 \mathrm{~K}$ intercept to the $4 \mathrm{~K}$ ring. Shield attachment is shown in Figure 3. Each thermal shield was instrumented with thermometers to record actual shield temperatures. System pressure was measured with Convectron gauges and Bayard-Alpert tubulated ion gauges. A computerized data acquisition system continuously monitored system temperatures, pressure, and support post heat load, and logged readings to disk on 30-minute intervals. 


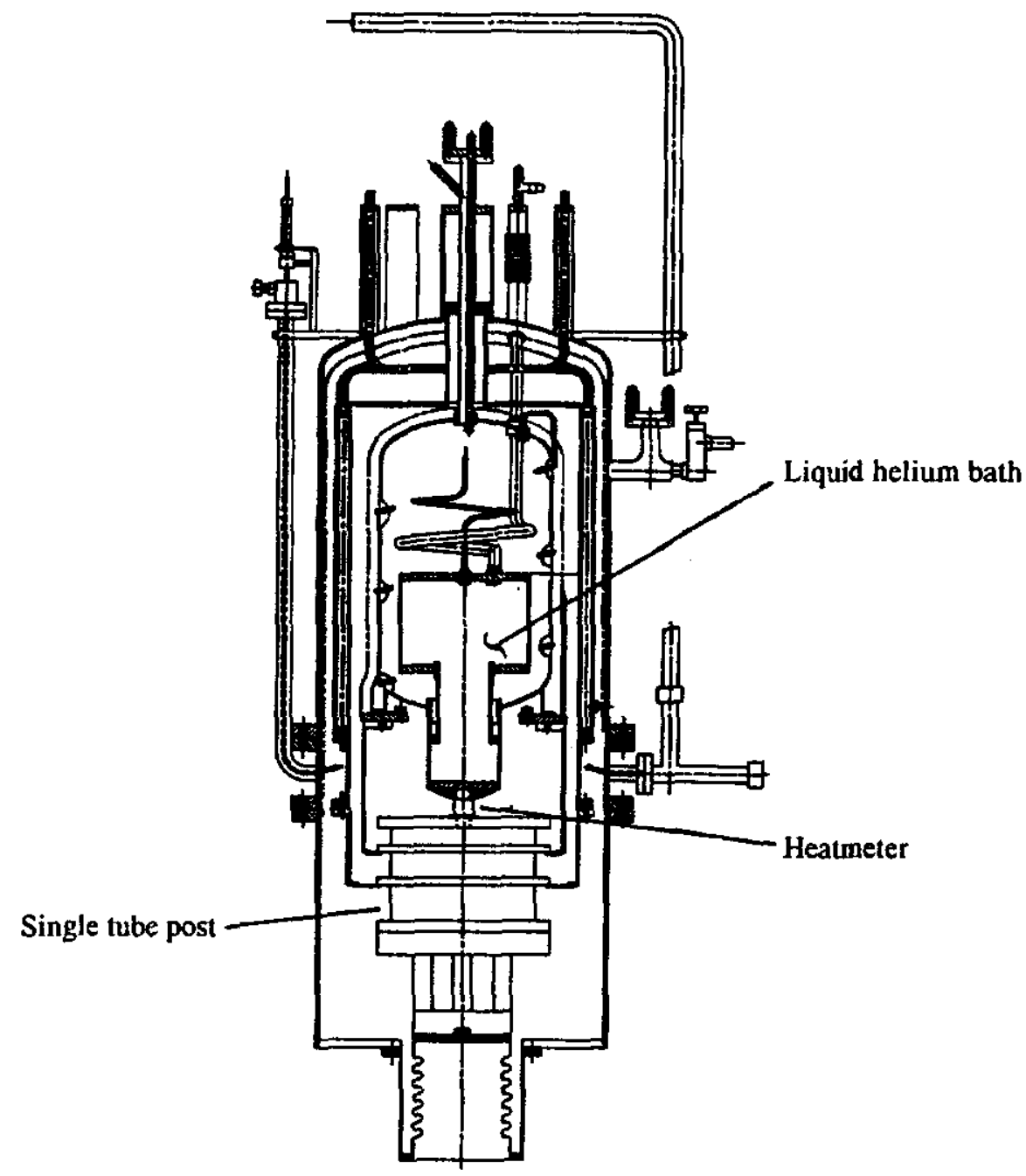

Figure 3. Heat leak measurement facility with single tube post.

\section{Measurement Results}

Table 4 presents a tabulated summary of the measurement data. Of primary interest is the total heat load to $4.2 \mathrm{~K}$ with the primary intercept operating near the design temperature of $20 \mathrm{~K}$. Two measurements were made with the primary intercept temperature near $20 \mathrm{~K}$; the measured heat load to $4.2 \mathrm{~K}$ was 0.030 and 0.029 watts respectively. Given that the $50 \mathrm{~mm}$ collider dipole heat load budget per support is 0.32 watts into $4.2 \mathrm{~K}$ with the primary intercept operating near the design temperature of $20 \mathrm{~K}$, the measured heat loads indicate that the single tube support meets the design budget.

Also included in Table 4 are calculated heat loads to the various heat stations for each data point. The calculations were made using measured temperatures, material properties, and physical dimensions of the finished post assembly. A comparison of measured and calculated heat load values is made in Table 5 with the design heat load budget for an SSC $50 \mathrm{~mm}$ collider dipole support post. Note that while the measured heat load to $4.2 \mathrm{~K}$ is below the design budget, all of the calculated values exceed the design budget. The disagreement between the $4.2 \mathrm{~K}$ measured vs. calculated value may be in part due to the thermal conductivity properties used for the composite tubes. Characterization of the specific composites used in this design may be required before truly accurate calculations of conductive heat load are achievable. 
Table 4. Summary of measurement data.

\begin{tabular}{|c|c|c|c|c|c|c|}
\hline & & \multicolumn{5}{|c|}{ Primary Intercept Temperature } \\
\hline Location & Sensor Type & $10 \mathrm{~K}$ & $\begin{array}{c}20 \mathrm{~K} \\
\text { (meas *2) }\end{array}$ & $\begin{array}{c}20 \mathrm{~K} \\
\text { (meas } \# I)\end{array}$ & $30 K$ & $40 \mathrm{~K}$ \\
\hline $4 \mathrm{~K}$ disc & Carbon resistor & 6.567 & 9.070 & 9.168 & 13.659 & 16.337 \\
\hline $4 \mathrm{~K}$ ring & Carbon resistor & 6.435 & 9.142 & 8.981 & 13.815 & 15.978 \\
\hline $20 \mathrm{~K}$ disc & Carbon resistor & 15.779 & 22.847 & 22.865 & 34.595 & 40.275 \\
\hline $20 \mathrm{~K}$ intercept & Carbon resistor & 9.924 & 19.142 & 19.162 & 31.752 & 37.439 \\
\hline $80 \mathrm{~K}$ disc & Platinum RTD & 85.798 & 85.664 & 85.859 & 86.355 & 86.531 \\
\hline $80 \mathrm{~K}$ intercept & Platinum RTD & 83.650 & 83.519 & 83.728 & 84.191 & 84.312 \\
\hline $300 \mathrm{~K}$ disc & Platinum RTD & 282.044 & 282.223 & 282.189 & 282.287 & 282.891 \\
\hline $300 \mathrm{~K}$ ring & Platinum RTD & 281.842 & 282.022 & 281.984 & 282.084 & 282.689 \\
\hline 20K shield & Carbon resistor & 8.311 & 19.118 & 19.140 & 33.357 & 39.852 \\
\hline $80 \mathrm{~K}$ shield & Platinum RTD & 81.730 & 81.611 & 81.816 & 82.262 & 82.340 \\
\hline Vacuum & Glass ion gauge & $1.36 \mathrm{E}-06$ & $1.34 \mathrm{E}-06$ & $1.67 \mathrm{E}-06$ & $1.34 \mathrm{E}-06$ & $1.04 \mathrm{E}-06$ \\
\hline $\begin{array}{l}\text { Heat load } \\
\text { to } 4.2 \mathrm{~K}(\mathrm{~W})\end{array}$ & Heat meter & 0.010 & 0.030 & 0.029 & 0.088 & 0.130 \\
\hline $\begin{array}{l}\text { Heat load } \\
\text { to } 4 \mathrm{~K} \text { ring }\end{array}$ & Calculated & 0.011 & 0.040 & 0.040 & 0.109 & 0.161 \\
\hline $\begin{array}{l}\text { Heat load to } \\
20 \mathrm{~K} \text { intercept }\end{array}$ & Calculated & 0.717 & 0.664 & 0.667 & 0.576 & 0.526 \\
\hline $\begin{array}{l}\text { Heat load to } \\
80 \mathrm{~K} \text { intercepl }\end{array}$ & Calculated & 3.708 & 3.714 & 3.710 & 3.707 & 3.720 \\
\hline
\end{tabular}

Table 5. Measured and calculated heat loads vs. design heat load budget.

\begin{tabular}{|c|c|c|c|}
\hline Thermal station & Budget heat load & $\begin{array}{c}\text { Measured } \\
\text { heat load }\end{array}$ & $\begin{array}{c}\text { Calculated } \\
\text { heat load }\end{array}$ \\
\hline $4 \mathrm{~K}$ & $0.032 \mathrm{~W}$ & 0.030 & 0.040 \\
\hline $20 \mathrm{~K}$ & $0.480 \mathrm{~W}$ & N/A & 0.667 \\
\hline $80 \mathrm{~K}$ & $3.160 \mathrm{~W}$ & N/A & 3.710 \\
\hline
\end{tabular}

Also of interest is the thermal gradient across the various shrink-fit joints of the support assembly. Table 6 presents the temperature gradient across the various thermal stations as a function of primary intercept temperature. There is very little temperature difference between the rings and discs that comprise the $4 \mathrm{~K}$ and $300 \mathrm{~K}$ thermal stations. As one might expect, there is a rather large thermal gradient across the $20 \mathrm{~K}$ thermal station. Recall that this is the point where the two composite tubes overlap, and as such the total composite tube thickness between these metal components is slightly larger than at the other joints. The overall composite tube thickness at the $20 \mathrm{~K}$ thermal station is approximately $4.41 \mathrm{~mm}$, whereas the composite tube thickness at the $4 \mathrm{~K}, 80 \mathrm{~K}$, and $300 \mathrm{~K}$ thermal stations is approximately $3.86 \mathrm{~mm}$. A more likely cause for the larger gradient is the presence of a third thermal joint between components at this thermal station. Not only are there thermal boundaries at the metal part-to-composite tube interfaces, but there is an interface between the GRP/FRP tubes. 
Table 6. Temperature gradients across the shrink-fit joints.

\begin{tabular}{|c|c|c|c|c|c|}
\cline { 2 - 6 } \multicolumn{1}{c|}{} & \multicolumn{5}{c|}{ Primary Intercept Temperature } \\
\hline $\begin{array}{c}\text { Thermal } \\
\text { station }\end{array}$ & $10 \mathrm{~K}$ & $\begin{array}{c}20 \mathrm{~K} \\
(\text { meas. \#2) }\end{array}$ & $\begin{array}{c}20 \mathrm{~K} \\
(\text { meas. \#I) }\end{array}$ & $30 \mathrm{~K}$ & $40 \mathrm{~K}$ \\
\hline $4 \mathrm{~K}$ & $0.132 \mathrm{~K}$ & $0.072 \mathrm{~K}$ & $0.187 \mathrm{~K}$ & $0.156 \mathrm{~K}$ & $0.359 \mathrm{~K}$ \\
\hline $20 \mathrm{~K}$ & $5.855 \mathrm{~K}$ & $3.705 \mathrm{~K}$ & $3.703 \mathrm{~K}$ & $2.843 \mathrm{~K}$ & $2.836 \mathrm{~K}$ \\
\hline $80 \mathrm{~K}$ & $2.148 \mathrm{~K}$ & $2.145 \mathrm{~K}$ & $2.131 \mathrm{~K}$ & $2.164 \mathrm{~K}$ & $2.219 \mathrm{~K}$ \\
\hline $300 \mathrm{~K}$ & $0.202 \mathrm{~K}$ & $0.201 \mathrm{~K}$ & $0.205 \mathrm{~K}$ & $0.203 \mathrm{~K}$ & $0.202 \mathrm{~K}$ \\
\hline
\end{tabular}

There is also a large thermal gradient across the $80 \mathrm{~K}$ thermal station. Recall that the $80 \mathrm{~K}$ intercept ring is stitch-welded to the $80 \mathrm{~K}$ shield, a connection that provides good thermal contact. In contrast, the $80 \mathrm{~K}$ inner disc is conductively cooled through the FRP tube section that is sandwiched between the $80 \mathrm{~K}$ ring and $80 \mathrm{~K}$ intercept. As the FRP tube is a good insulator, and since cooling is occurring from the $80 \mathrm{~K}$ intercept, it holds that a substantial thermal gradient should exist across the insulated connection.

Overall, the temperatures of the metal components at each joint tracked each other closely during thermal cycling, thereby indicating that the structural integrity of the joints will remain intact during periods of transient thermal conditions.

\section{CONCLUSIONS}

Prototype single tube support posts have been successfully assembled and tested under conditions simulating those encountered during cryostat operation and magnet shipping and handling. Assembly experience indicates that the single tube design is easier to assemble than the reentrant post design. Fewer shrink-fit joints are required in the single tube design and the joints that are required have less stringent manufacturing tolerances.

Structural performance results indicate that the single tube post design meets the structural criteria set forth for the $50 \mathrm{~mm}$ CDM and offers a stiffer suspension system than the reentrant post design. In an attempt to test to failure, a lateral of load of $4536 \mathrm{~kg}$ was applied to the single tube post assemblies. There was no sign of post failure at this loading level, which is the maximum lateral load capacity of the test apparatus.

The measured heat load of 0.030 watts into $4.2 \mathrm{~K}$ indicates that the single tube support post meets the thermal design budget of 0.032 watts to $4.2 \mathrm{~K}$. The calculated heat loads into both the $20 \mathrm{~K}$ and $80 \mathrm{~K}$ thermal stations exceed the design budget by a substantial amount. This may be due in part to the use of thermal properties data that is not truly representative of the composite materials used in the design. An alternate measurement scheme has been proposed in which heat meters would be installed to measure the heat load into each temperature station. This needs to be considered further if actual verification of heat loads into the $20 \mathrm{~K}$ and $80 \mathrm{~K}$ thermal stations is required.

\section{REFERENCES}

1. T.H. Nicol, "SSC $50 \mathrm{~mm}$ collider dipole cryostat single tube support post conceptual design and analysis," presented at the Fourth Annual IISSC Conference, New Orleans, LA, March 4-6, 1992.

2. J.D. Gonczy, et al., Heat leak measurement facility, in: "Advances in Cryogenic Engineering," Vol. 31, Plenum Press, New York, (1986), p. 1291. 